\title{
Procedimentos de escrita e manejo de pigmentos: uma leitura de Esperando Godot e Fim de Jogo de Samuel Beckett
}

Sônia Maria Materno de Carvalho

Recebido em 31/05/2011 - Aprovado em 25/08/2011

\section{Resumo:}

Este trabalho analisa as peças Esperando Godot e Fim de Jogo de Samuel Beckett, investigando de que modo, nesses textos, os procedimentos de escrita dramatúrgica incluem a rigorosa construção de uma visualidade cênica, pautada pela redução do espaço cênico, pelo apagamento dos corpos, pela insistência da obscuridade e pela configuração de um palco monocromático.

Palavras-chave: teatro; imagem; Beckett. 
Eu compreendi que meu caminho se fazia no sentido do empobrecimento, na falta de conhecimento e em diminuir, antes em subtrair que adicionar.

Samuel Beckett

Há na obra teatral de Beckett (como indica a epígrafe) um recorrente processo de redução, de subtração do que é mostrado ou falado em cena.

Assim, o espaço de representação é sempre exíguo, reduzido e com poucos elementos cênicos: um trecho de estrada quase deserto (Esperando Godot) ou um cubículo mal iluminado (Fim de $J o g o$ ). O gestual dos personagens é geralmente repetitivo (retirar o sapato, recolocá-lo, colocar e retirar o chapéu, permanecer em cena querendo ir embora --“"Vamos / não podemos / por quê? / estamos esperando Godot" (diz Estragon a Vladimir). ${ }^{1}$

As réplicas são curtas e oferecem ao leitor e/ou espectador referências espaço-temporais imprecisas (uma estrada - Esperando Godot) ou mesmo indeterminadas (interior sem móveis - Fim de Jogo). É como se, em relação às peças de Beckett, pudéssemos fazer as mesmas perguntas que o narrador do romance beckettiano intitulado O Inominável faz no início da narrativa: "Onde agora? Quando agora? Quem agora?" (BECKETT, 1989, p. 5).

Há também na cena de Samuel Beckett muitas pausas, interrupções, instantes de silêncio, ruídos estranhos, palavras e vozes brincando com repetições silábicas (Didi, Gogo, Pozzo. Vladimir compreende Bozzo e diz que conheceu uma família Gozzo), ou ainda palavras produzindo sonoridades (Nagg, Nell, personagens de Fim de Jogo).

Notamos também a presença de cores, cores neutras, discretas, com uma predominância de variações do cinza. Há também o apagamento progressivo do corpo dos personagens, ora enterrados em latões (Nagg e Nell), ora na areia, como Winnie em Dias Felizes, ora em urnas como na peça Comédia (os personagens estão dentro de urnas, visíveis apenas da cintura para cima). São corpos parcialmente vistos, pouco iluminados, quase sempre imobilizados.

É, então, nesse caminhar rumo ao pouco, ao menos, ao quase nada, é nesse palco em que os personagens são quase apagados ou estão semi-encobertos, é nesse limiar do quase que a peça se configura e os personagens se constituem e insistem, visualmente expostos, atuando, até o fim do jogo, sem sair de cena, sem abandonar o palco, sempre lá, até o apagar da pouca luz que os ilumina.

Vamos, então, a algumas datas. Esperando Godot foi encenada pela primeira vez em 5 de janeiro de 1953, no teatro da Babilônia. Dois andarilhos, Vladimir e Estragon, aguardam, perto de uma árvore esquelética, um terceiro personagem de nome Godot, que anuncia sua vinda mas nunca vem. Em cada ato, dois outros andarilhos - Pozzo e Lucky - apresentam-se e contracenam com Didi e Gogo. 
Esperando Godot representou para Beckett um divisor de águas, o fim do anonimato e da penúria e o início do reconhecimento literário e do sucesso financeiro.

Mas o sucesso de Godot não garantiu recursos para a encenação parisiense de Fim de Jogo. Essa peça foi encenada pela primeira vez em Londres no dia $1^{\circ}$ de abril de 1957, no Royal Court Theatre, em francês. Depois do sucesso em Londres, o Studio des Champs-Elysées ofereceu acolhida e no final de abril do mesmo ano Fim de Jogo foi encenada em Paris. Foram 97 representações e a interrupção se deu por fadiga dos atores.

Diferentemente de Esperando Godot, que se passa ao ar livre (um trecho de estrada), a cenografia de Fim de Jogo exibe um cômodo fechado, que pode ser um quarto, uma sala, um refúgio, enfim, um lugar ainda habitável, um interior sem móveis, como indica a rubrica.

Quando as cortinas se abrem, Hamm, paralítico e cego, está no centro do palco, sentado em sua cadeira de rodas, coberto por um lençol. À esquerda, dois latões de lixo, recobertos por um outro lençol e dentro deles Nagg e Nell, pais de Hamm. A única figura ereta que se movimenta com um certo desembaraço em cena, mas manca, é Clov, um misto de filho adotivo e empregado de Hamm.

Quando o espetáculo se inicia, Clov retira os lençóis e diz: "Acabou, está acabado, isto vai acabar, isto vai talvez acabar", ou seja, passado (acabou) e futuro (isto vai acabar) entrelaçados e determinados pela palavra fim. Mas o que acaba? O que já acabou? O mundo? A vida? O teatro? Trata-se de um jogorepresentação já perdido antes mesmo de iniciado? Então por que encenar? Porque apesar de tudo é preciso continuar. Cito aqui as últimas frases do texto O Inominável: -- "Não posso continuar, vou continuar" (BECKETT, 1989, p. 137). Continuar, ou seja, esperar como se faz em Godot ou representar (encenando a própria precariedade da representação) como se faz em Fim de Jogo.

\section{Manejo de pigmentos: branco sombreado, preto claro e cinza chumbo.}

"Descrever, destecer o quê? As nuances" Roland Barthes (O neutro)

"Uma névoa encardida enchia todo o espaço" Charles Baudelaire ("Os sete velhos" - Flores do Mal)

O palco beckettiano é quase sempre um lugar saturado pela cor cinza. Mas nesse universo quase monocromático há nuances.

Optando, então, de forma mais focada por esse eixo investigativo, inicio minha análise por Fim de Jogo. A rubrica informa: interior sem móveis à meia-luz. (luz acinzentada), ou seja, ambiente mal iluminado, sombrio e austero. 
Abro aqui um parentese para citar três outras rubricas de outra três peças beckettianas que evidenciam uma opção por proposta de monotonia cromática.

Em Fragmentos de monólogo (publicada em 1979) lê-se: "fraca luz difusa (...). Locutor no centro do palco (...). Cabelos brancos em desordem, roupa longa de dormir branca e meias brancas grossas". (BECKETT, 1986, 29) ${ }^{2}$

Em Aquela Vez (publicada em 1976) a rubrica informa: "Palco no escuro, luz sobre o rosto do ouvinte (...) velho rosto branco (...), longos cabelos brancos eriçados como se vistos do alto, espalhados sobre um travesseiro". (BECKETT, 1986, 9)

Em Passos (publicada em 1976), vemos em cena a figura da personagem May. "Cabelos cinza em desalinho, penhoar cinza esfarrapado, escondendo os pés". (BECKETT, 1978, 7)

Voltando a Fim de Jogo, a cena mostra um cubículo, pode ser um abrigo, e nesse lugar vivem quatro pessoas: Hamm (cego e paralítico), Clov (coxo), Nagg e Nell (mutilados). Há janelas altas que estabelecem a ligação entre o fora e o dentro. Por essas janelas, Clov, o único que anda, vê com sua luneta o entorno do abrigo, segundo Hamm "o outro inferno". Mas o que Clov vê? "Zero... Zero... Zero..." e, mais adiante, acrescenta: "Ondas? De chumbo. O tempo está cinza, cinza! Ciiinza".

Tudo nesse cubículo está acabando: remédios, alimentos, caramelos, calmantes. Não se pode trazer de fora o que está acabando dentro, porque o acolá é vago, amedrontador e parece vazio. Perscrutando de tempos em tempos esse exterior, com sua luneta, Clov o define: Zero, Nada, Cinza.

Então a grisalha domina o dentro e o fora. O abrigo é um ponto de luz (pálida) em meio a uma imensidão escura e quase deserta.

O manejo de pigmentos estabelece as cores do cenário. Fora é o cinza chumbo ou o preto escuro e dentro, o branco sujo ou sombreado (dos lençóis velhos que recobrem os lugares da ação no início da peça). Mas é o cinza opaco do ambiente à meia-luz que dá o tom à cena.

E nesse palco viciado em cinza, há um elemento de cor vibrante, há um objeto escarlate. Trata-se de um lenço vermelhosangue, manchado de sangue, que recobre o rosto de Hamm. Então, sentado em uma cadeira de rodas no centro do palco, Hamm inicia o jogo teatral - "minha vez de representar", e segurando o lenço manchado de sangue, retirado do rosto, diz: "Velho trapo!".

Esse lenço vermelho-sangue sinaliza a cortina de boca de cena - geralmente, nos antigos teatros, de veludo vermelho, ponto inaugural da representação.

Inaugural mas também final, pois o espetáculo se encerra

2 A tradução da rubrica inicial dessas três peças é minha. com o fechar das cortinas. Em Fim de Jogo, o lenço-cortina-vermelho-sangue volta às mãos de Hamm, no final da peça, que o 
mantém aberto diante dele - "Velho trapo! Você fica" - aproxima o lenço de seu rosto e a rubrica indica "Cortina".

Assim, o vermelho que margeia a peça (aparece no início e no fim do jogo teatral) é a única cor vibrante que ganha letra nos dois textos aqui estudados. Em Esperando Godot, no segundo ato, lemos: "lá longe tudo é vermelho" diz Vladimir a Estragon, afirmando que ambos trabalharam, antes de esperarem por Godot nessa estrada em algum canto do mundo, em uma região chamada de Roussillon, na época da colheita da vinha.

O vermelho é a única cor exuberante numa paleta que privilegia o tom sobre tom ou as variações em torno de cores neutras (branco sujo, preto claro, cinza chumbo), cores menos prezadas. Mas o vermelho não se impõe no palco, é, talvez, uma flutuação eventual, uma presença ligeira, uma marcação de cena, quem sabe? A cor do início e do fim do espetáculo, ou a cor das bordas que limitam a representação.

É interessante notar que as cores primárias, isto é, o vermelho dos vinhedos e o azul pálido do mar - Estragon diz no primeiro ato: "Eu me lembro dos mapas da Terra Santa. Em cores. Muito bonitas. O mar morto era azul pálido (...) eu me dizia, é lá que iremos passar nossa lua de mel. Nadaremos. Seremos felizes" - aparecem nessa peça sempre referidas a um tempo anterior ao tempo de cena. Inscrevem-se na memória dos personagens.

A cor neutra é dada a ver, nos diz Barthes em seu texto O Neutro, quando se esconde o colorido. Mas quando não há o colorido, quando a pouca cor é uma proposta cênica, sobram as nuances do cinza. E nessa paleta pouco variada, em que o cinza rouba a cena e furta a cor, que os tons acinzentados convocam os espectadores a procurarem a ligeira diferença do tom sobre tom, essas variações do cinza obrigam os espectadores a lidarem com o indistinto, com o parecido. E esse esforço, para diferenciar cores quase idênticas, exige do espectador a observância do manejo de pigmentos do autor.

Vemos, assim, o cinza recobrindo corpos, entrando na opção do colorido das roupas. São corpos que exibem roupas desbotadas: preto fouveiro, branco sujo, cinza-esverdeado. Na primeira encenação de Esperando Godot, objetos de cena vieram dos depósitos de lixo de Paris e, dessa forma, o resto entrava literalmente em cena.

Les deux clochards étaient vêtus, l'un Vladimir d'une très vieille redingote noire, élimée, verdâtre, l'autre Estragon d'un aussi vieux pantalon de velours retenu par une ficelle (...) les chapeaux melons, hors d'âge. Tout cela noirâtre, tirant sur le verdâtre. (tradução minha).
Em Esperando Godot Vladimir usava um velho redingote preto, de tecido desgastado, manchado, cinza-esverdeado e Estragon uma velha calça de veludo amarrada por um barbante. Ambos usavam chapéu "coco" fora de moda, tudo de cor preto fouveiro ou preto esverdeado. ${ }^{3}$ (BECKETT, 1999, 34).

A carnação do cinza (o cinza em corpos) também pode ser observada na cena beckettiana no que diz respeito ao alimento. Os legumes que freqüentam os bolsos de Didi e Gogo, o único 
alimento desses personagens em cena, perderam, há muito, suas cores, seu viço. O tempo e o local de armazenamento os desbotaram, acinzentando a casca dos legumes, que se apresentam escurecidos, assemelhados ou pouco diferenciados, indistintos talvez.

Lemos no primeiro ato: Estragon - "Dê-me uma cenoura / Obrigado / Oh! É um nabo". Ou no segundo ato: diálogo entre Vladimir e Estragon --“"Você quer um rabanete? / É tudo o que há? / Há rabanetes e nabos / Não há mais cenouras? / Não (, / Então me dá um rabanete. Ele está preto / É um rabanete / Só gosto dos cor de rosa".

Em Esperando Godot, a indicação cênica aponta: "Noite". Trata-se, assim, de um crepúsculo que vai se adensando. "É sempre ao cair da noite" (diz Vladimir a Estragon no segundo ato) que o encontro pode ocorrer. Ora, esse espaço noturno, aclarado apenas pela luz da lua, assemelha-se, no teatro, ao espaço destinado à platéia, imersa na obscuridade. Cria-se, então, pelo efeito da escassez da luz no palco, um espaço integrado ou extensivo que aproxima atores e público, repelindo a alternância tradicional entre luminosidade (palco) e obscuridade (público). Em Fim de Jogo, o caráter extensivo do cinza une o dentro e o fora de cena (entrevisto por Clov com sua luneta). Como Clov vê o fora, estando dentro? Zero, Nada, Cinza. Mas quando muda a direção da luneta, quando a dirige para a platéia, Clov exclama surpreso (e de forma irônica, claro): "ah, começa a ficar alegre, vejo uma multidão em delírio". Neste momento, Clov é o espectador e o público, tomado à sua revelia, torna-se parte integrante do jogo teatral. E a provocação continua: "Então? Agora ninguém ri?".

A cor neutra para Barthes também pode ser chamada de furta-cor, isto é, ela não propõe a cor, ela muda sutilmente de matiz, talvez de sentido, segundo a observação do sujeito que olha.

Então é preciso que o espectador de Beckett seja tocado e se mexa ou mexa os olhos e procure na obscuridade do palco a variação de tons cuidadosa e economicamente proposta pelo autor. Porque a grisalha não é falta de cor, a grisalha não é incolor e portanto invisível, a grisalha é a cor não marcada, é a cor que desliza e bordeja - sem se confundir com ela - a indistinção.

Ela é nuance, matiz à margem da cor, no limiar da cor. Não é falta de opção, é antes um desejo de por um fim na opulência da cor e na intensidade do fluxo luminoso. É, segundo Barthes, em $O$ Neutro, um despegamento do sentido ou um desejo de des-pigmentar, cinzar, acinzentar, dizemos nós, ou dar a ver cinzas, ou seja, destroços (o que sobrou de uma moradia), ruínas vivas, resto, sobra, franja do humano que sobrevive e espera, num trecho de uma certa estrada ou num quartinho no fim do mundo, o fim do jogo. 
Assim, o teatro de Beckett tem por proposta o despojamento, isto é, mostrar o mínimo e dizer pouco. Mas esse a menos deixa ver a intensidade de um trabalho que consegue, a cada texto, nos surpreender, porque a cada texto apresenta uma tentativa de "falhar melhor". (BECKETT, 1988, 7)

Para finalizar, o que está em jogo, enfim, no palco beckettiano é a representação e sua opacidade. Imobilizados em cena, seja pela espera, seja pela impotência física ou por não ter a chave da despensa, Didi, Gogo, Hamm, Nagg, Nell, Clov (fragmentos de nomes próprios) são, entretanto, figuras cênicas não fixadas em objetos representacionais. Não representam algo ou alguém: "Significar? Nós, significar! (riso breve). Ah, essa é boa!" (diz Clov no segundo ato). Não são figuras translúcidas que exibam uma transparência representativa. São figuras cobertas, opacas, sombrias. Também não há um fora de cena que ajude a significar a cena.

Articulam-se, assim, no palco de Beckett uma obscuridade sensorial (cena pouco iluminada) e uma obscuridade significante, produzida pela indeterminação das referências contextuais e também pela própria problematização da noção de sentido que o seu teatro opera. Este, o sentido, não se pode deduzi-lo ou descobri-lo. Ele é constituído pelo leitor/espectador num jogo de perde e ganha que se faz nessa tensão entre o que é dado a ver e o que é subtraído do olhar.

\begin{abstract}
:
This text is intended as a study of Samuel Beckett's theatre done in the perspective of an analysis of the visual dimension of the plays Waiting for Godot and Endgame. The attention will be focused on body's fragmentation, space's reduction and on the economy of gesture and colors with an emphasis on the Beckett's insistence on the obscure and monochromatic stage.
\end{abstract}

Keywords: theatre; image; Beckett.

\title{
REFERÊNCIAS
}

BARTHES, Roland. O Neutro. Anotações de aulas e seminários ministrados no Collège de France, 1977-1978. Texto estabelecido, anotado e apresentado por Thomas Clere. Trad. Ivone Castilho Benedetti. São Paulo: Martins Fontes, 2003.

BAUDELAIRE, Charles. "Les septs vieillards". In: Les Fleurs du Mal. Paris: Librairie Générale Française, 1972.

. "Os sete velhos". In: Poesia e Prosa. Edição organizada por Ivo Barroso. Rio de Janeiro: Nova Aguilar, 1995. 
BLANCHOT, Maurice. "Agora onde? Agora quem?" In: O livro por vir. Trad. Maria Regina Louro. Lisboa: Relógio D’Água, 1984. BECKETT, Samuel. En attendant Godot. Paris: Les Éditions de Minuit, 1952.

. Fin de Partie. Paris: Les Éditions de Minuit, 1957.

. Comédie et Actes divers (Va-et-vient, Cascando, Paroles et musique, Dis Joe, Actes sans paroles I et II, Film et Souffle). Paris: Les Éditions de Minuit, 1966.

. Oh! Les beaux jours suivi de Pas Moi. Paris: Les Éditions de Minuit, 1975.

Cahier de L'Herne. Dirigé par Tom Bishop et Raymond Federman. Paris: Éditions de L'Herne, 1976.

Pas suivi de Fragment de théâtre I et II, Pochade radiophonique- Esquisse radiophonique. Paris: Les Éditions de Minuit, 1978.

Catastrophe et autres dramaticules (Cette fois, Solo, Berceuse, Impromptu d'Ohio, Quoi ou). Paris: Les Éditions de Minuit, 1986.

. Pioravante Marche. Trad. Miguel Esteves Cardoso. Edição bilíngüe. Lisboa: Gradiva, 1988.

. O Inominável. Trad. Waltensir Dutra. Rio de Janeiro: Nova Fronteira, 1989.

. Tous ceux qui tombent. Paris: Les Éditions de Minuit, 1957.

CAVALCANTI, Isabel. Eu que não estou aí onde estou: o teatro de Samuel Beckett (o sujeito e a cena entre o traço e o apagamento). Rio de Janeiro: 7 Letras, 2006.

KNOWLSON, James. Beckett. Biographie traduite de l'anglais par Oristelle Bonis. Paris: Actes Sud, 1999.

KUDIELKA, Robert. “O paradigma da pintura moderna na poética de Beckett: uma arte que não se ressente de sua insuperável indigência." Trad. José Marcos Macedo. In: Revista da Cebrap, Novos estudos, n. 56, São Paulo, março 2000.

MARTIN, Jean. "En créant Godot". In: Magazine littéraire n 372, janvier 1999, pgs. 52/57.

PETEL, Gilles. “Des mots et des larmes". In: Critique. N. 46, 1990.

SALADO, Régis. "On n'est pas liés? Formes du lien dans En attendant Godot et Fin de Partie." In: Samuel Beckett: l'écriture et la scène. Onze études réunies et présentées par Evelyne Gossman et Régis Salado. Paris: SEDES, 1998.

REVISTAS

Magazine Littéraire no 372, janvier/1999. Dossier Beckett. Magazine Littéraire no 231, juin/1986. Dossier Beckett. 